\title{
Spotlight on maternal mental health: a prepandemic and postpandemic priority
}

\section{Liz Bailey, ${ }^{1}$ Kerry Gaskin ${ }^{2}$}

10.1136/ebnurs-2021-103378

${ }^{1}$ Elizabeth Bryan Cenre for Multiple Births, Birmingham City University, Birmingham, UK ${ }^{2}$ Midwifery and CPD, University of Worcester, Worcester, UK

Correspondence to: Dr Liz Bailey, Maternity, University Hospitals Coventry and Warwickshire NHS Trust, Coventry CV2 2DX, UK; elizabeth. bailey@bcu.ac.uk
Annually in May, there is a spotlight on maternal mental health (MMH) globally. In the UK, MMH awareness week is coordinated by the perinatal mental health partnership (@PMHPUK) (3 May 2021 to 9 May 2021) ${ }^{1}$; while in the USA, 'The Blue Dot Project' uses a blue dot as a symbol for unity and awareness for those living with mental health (MH) conditions. ${ }^{2}$ This annual focus enables professionals, stakeholders and individuals to raise awareness and influence policy on this critical issue. Evidenced based nursing will be supporting MMH Awareness week by publishing a series of blogs representing a range of views during May 2021.

Perinatal mental health (PMH) encompasses any $\mathrm{MH}$ condition affecting people during pregnancy and in the first year after having a baby. ${ }^{3}$ This includes conditions ranging from mild depression and anxiety to psychosis; pre-existing $\mathrm{MH}$ and $\mathrm{MH}$ recurrence during pregnancy. ${ }^{3}$ PMH conditions can be pregnancy specific such as tokophobia (fear of childbirth), or postpartum traumatic stress disorder; or be more generalised, and range in the degree to which they can impact on quality of life. In general, PMH conditions affect 10-20\% of pregnancies, although reported prevalence rates differ by classification and severity of disease. ${ }^{4}$

Those with mild to moderate PMH conditions may self-manage using strategies such as journaling ${ }^{5}$ and mindfulness. ${ }^{6}$ Techniques to prepare for labour, such as hypnobirthing may have an impact on anxiety fear. ${ }^{7}$ Medical treatment must be considered in parallel with individual medical history and decision-making should happen in partnership with a PMH specialist. ${ }^{3}$ Access to specialist services is essential; in 2015 a task force highlighted gaps in service provision across the UK. ${ }^{8}$ Following investment, services improved supported by an ongoing campaign to "turn the map green." Many $\mathrm{PMH}$ teams are multidisciplinary, with psychiatrists, $\mathrm{MH}$ nurses, social workers and nursery nurses, ${ }^{10}$ however, little evidence exists on the most effective model of community and inpatient care and access to services varies globally. ${ }^{10}$ Acceptance and stigma are also barriers to care for $\mathrm{MH}$ conditions, which the campaign for awareness hopes to address. ${ }^{11}$

Identification and opportunity for disclosure of $\mathrm{MH}$ concerns should remain a priority for healthcare professionals with use of mandatory inquiry and screening tools common practice. ${ }^{12}$ Additionally, opportunities for active listening are required to facilitate disclosure, following which a sensitive and effective response is needed, underpinned by healthcare staff awareness and training.

Stressful life events are associated factors in the development of PMH issues ${ }^{3}$ and the last 12-18 months have been stressful for families everywhere. On 12 January 2020, the WHO confirmed a novel coronavirus, later to be named SARS-CoV-2 or COVID-19. The Royal
College of Obstetricians and Gynaecologists and Royal College of Midwives rapidly produced clinical guidance for doctors, midwives prioritising the reduction of transmission of COVID-19 to pregnant women and the provision of safe care to women with suspected/confirmed COVID-19. ${ }^{13}$ Many pregnancies would be impacted globally. ${ }^{14}$ The priority was to reduce social contact reducing the number of antenatal and postnatal contacts in the $\mathrm{UK}^{15}$ and elsewhere. Many hospital services were reconfigured due to the unprecedented demands, with more than a fifth of birthing centres and a third of homebirth services closed due to midwifery shortages. ${ }^{16}{ }^{17}$ There were calls for the focus of healthcare professionals to be on social support for mothers during lockdown ${ }^{18}$; recognising that sources of support help mothers to maintain their own $\mathrm{MH}$ and their capacity to cope with the demands of being a mother. ${ }^{18}$ Survey respondents $(n=1451)$ identified potential barriers including 'not wanting to bother anyone', 'lack of wider support from allied healthcare workers' and concerns such as acceptability of virtual antenatal clinics, the presence of birthing partners and rapidly changing communication methods. ${ }^{19}$ Several recently published papers report similar results of online surveys undertaken during the lockdown in various countries. ${ }^{20-22}$

There is a need for extra vigilance as we remain in and recover from the pandemic. Maternal suicide remains the leading cause of direct deaths occurring in the year after the end of pregnancy, ${ }^{23}$ with psychiatric illness (including drugs and alcohol related deaths) being the fourth overall cause of death after cardiac, thrombosis and neurological causes. ${ }^{23}$ Sadly, a recent UK report ${ }^{24}$ identified that four women died by suicide during March to May 2020, echoing concerns raised in previous mortality reports. ${ }^{23}$ Data from Australia ${ }^{25}$ and the USA indicate a similar trend, with organisations such as 2020mom campaigning for the USA to begin tracking maternal suicide rates. ${ }^{26} \mathrm{~A}$ review of perinatal suicides in Canada over 15 years, ${ }^{27}$ found that mood or anxiety disorders (rather than psychotic disorders) were common, and more lethal means (hanging or jumping) were used than in non-perinatal suicides indicating suicidal intent. ${ }^{27}$

Healthcare professionals should not underestimate the potential consequences of declining $\mathrm{PMH}$ and should be vigilant to screen, enquire and refer. COVID-19 has resulted in changes to service provision, face to face contacts as well as significant depletion in the $\mathrm{MH}$ of the National Health Service workforce. ${ }^{28}$ Now more than ever, campaigning on MMH needs to focus on awareness, action and policy, to support those in need of support and those required to provide it. Join us with \#maternalMHmatters (w/c 843).

Twitter Liz Bailey@Liz8ailey and Kerry Gaskin @ GaskinKerry 
Funding The authors have not declared a specific grant for this research from any funding agency in the public, commercial or not-for-profit sectors.

Competing interests None declared.

Patient consent for publication Not required.

Provenance and peer review Commissioned; internally peer reviewed.$$
\text { (2) }
$$$$
\text { OPEN ACCESS }
$$

Open access This is an open access article distributed in accordance with the Creative Commons Attribution Non Commercial (CC BY-NC 4.0) license, which permits others to distribute, remix, adapt, build upon this work non-commercially, and license their derivative works on different terms, provided the original work is properly cited, appropriate credit is given, any changes made indicated, and the use is non-commercial. See: http://creativecommons.org/licenses/by-nc/4.0/.

- Author(s) (or their employer(s)) 2021. Re-use permitted under CC BY-NC. No commercial re-use. See rights and permissions. Published by BMJ.

\section{References}

1 Perinatal mental health partnership. Available: https://perinata Imhpartnership.com/ [Accessed 26 Jan 2021].

2 The blue dot project. Available: https://www.thebluedotproject. org/ [Accessed 26 Jan 2021].

3 O’Hara MW, Wisner KL. Perinatal mental illness: definition, description and aetiology. Best Pract Res Clin Obstet Gynaecol 2014;28:3-12.

4 Maternal mental health alliance. The issue, perinatal mental illness. Available: https://maternalmentalhealthalliance.org/ about/the-issue/ [Accessed 26 Jan 2021].

5 Godfrey-Issacs L. Maternal Journal - creative journaling All4maternity February 2018. Available: https://www. all4maternity.com/maternal-journal-creative-journaling/

6 Warriner S, Crane C, Dymond M, et al. An evaluation of mindfulness-based childbirth and parenting courses for pregnant women and prospective fathers/partners within the UK NHS (MBCP-4-NHS). Midwifery 2018;64:1-10.

7 Downe S, Finlayson K, Melvin C, et al. Self-Hypnosis for intrapartum pain management in pregnant nulliparous women: a randomised controlled trial of clinical effectiveness. BJOG 2015;122:1226-34.

8 NHS England. Implementing the five year forward view for mental health NHS England, 2016. Available: https://www. england.nhs.uk/wp-content/uploads/2016/07/fyfv-mh.pdf [Accessed 26 Jan 2021].

9 Maternal mental health alliance. Uk specialist perinatal mental health community teams (2019 data). Available: https://mate rnalmentalhealthalliance.org/campaign/maps/ [Accessed 26 Jan 2021].

10 Howard LM, Khalifeh H. Perinatal mental health: a review of progress and challenges. World Psychiatry 2020;19:313-27.

11 Rodger D. Impact of stigma on the care of postpartum women with severe mental illness. Evid Based Nurs 2019;22:81.

12 National Institute for Health and Care Excellence. Antenatal and postnatal mental health: clinical management and service guidance (CG 192) 2014 (updated 2020). Available: https://www.nice.org.uk/guidance/cg 192 [Accessed 26 Jan 2021].

13 Royal College of Obstetricians and Gynecologists. Royal College of midwives, coronavirus (COVID-19) infection and pregnancy RCOG and RCM, 2020. Available: https://www.rcog. org.uk/coronavirus-pregnancy [Accessed 26 Jan 2021].

14 Wells P, Taylor A, Battersby C. Practical considerations for the emergency delivery of babies from mothers with confirmed or suspected COVID-19. Infant 2020;16:94-8.

15 Richens Y, Wilkinson M, Connor D. Guidance for the provision of antenatal services during the COVID-19 pandemic. $\mathrm{Br} \mathrm{J}$ Midwifery 2020;28:324-7.

16 Tingle J. COVID-19 safety in maternity care: lessons for the whole NHS. Br J Nurs 2020;29:486-7.

17 Summers H. Expectant mothers turn to free birthing after home births cancelled. Available: https://tinyurl.com/vc87zvj [Accessed 19 Jan 2021].

18 Oates J. Promoting infant mental health through focusing on social support for mothers during lockdown, 2020. Available: https://ihv.org.uk/news-and-views/voices/promoting-infantmental-health-through-focusing-on-social-support-formothers-during-lockdown/ [Accessed 29 Jan 2021].

19 Karavadra B, Stockl A, Prosser-Snelling E, et al. Women's perceptions of COVID-19 and their healthcare experiences: a qualitative thematic analysis of a national survey of pregnant women in the United Kingdom. BMC Pregnancy Childbirth 2020;20:600.

20 Dib S, Rougeaux E, Vázquez-Vázquez A, et al. Maternal mental health and coping during the COVID-19 lockdown in the UK: data from the COVID-19 new Mum study. Int J Gynaecol Obstet 2020;151:407-14.

21 Davenport MH, Meyer S, Meah VL, et al. Moms are not OK: COVID-19 and maternal mental health. Front Glob Womens Health 2020;1.

22 Best Beginnings. Home-Start UK, and the parent-infant Foundation (2020) babies in Lockdown: listening to parents to build back better. Available: https://babiesinlockdown.info/ [Accessed 19 Jan 2021].

23 Knight M, Bunch K, Tuffnell D. Improving Mothers' Care Lessons learned to inform maternity care from the UK and Ireland Confidential Enquiries into Maternal Deaths and Morbidity 2016-18. 0xford: National Perinatal Epidemiology Unit, University of, 2021. https://www.npeu.ox.ac.uk/assets/ downloads/mbrrace-uk/reports/maternal-report-2020/ MBRRACE-UK_Maternal_Report_Dec_2020_v10.pdf

24 Knight M, Bunch K, Cairns A. Saving Lives, Improving Mothers' Care Rapid Report: Learning from SARS-CoV-2-related and associated maternal deaths in theUK March - May 2020. Oxford: National Perinatal Epidemiology Unit, University of Oxford, 2020. https://www.npeu.ox.ac.uk/assets/downloads/ mbrrace-uk/reports/MBRRACE-UK_Maternal_Report_2020_ v10_FINAL.pdf

25 Australian Institute of Health and Welfare 2020. Maternal deaths in Australia. cat. No. per 99. Canberra: AIHW, 2020. https://www.aihw.gov.au/reports/mothers-babies/maternaldeaths-in-australia

262020 Mom Maternal suicide. Suicide facts and figures: United States 2020. Available: https://www.2020mom.org/maternalsuicide

27 Grigoriadis S, Wilton AS, Kurdyak PA, et al. Perinatal suicide in Ontario, Canada: a 15-year population-based study. CMAJ 2017;189:E1085-92.

28 Greenberg N, Weston D, Hall C. Mental health of staff working in intensive care during COVID-19. Occup Med 2020. 